\title{
Evaluating the Relationship Between Work Engagement, Work Alienation and Work Performance of Healthcare Professionals
}

\author{
Farhat Alyas \\ Post RN , the superior college ( Department Of Nursing)
}

\begin{abstract}
s
Background: work alienation and work engagement have relationship with the performance of healthcare worker in the hospitals. Objectives: The thought to have study in the health care organization areas for detecting a co- relation in work enthusiasm and in cut off jobs demands. It has also to check connection in work devotion, disappointment by not full fill it anticipated goals and shadow on actions. Methods: It is a quantitative corelational research design was designed on 142 people of children hospital and ICH Lahore, using adopted questionnaires with questions on work alienation,work engagement and work performance . A data were analyzed using SPSS (statistical package for social science studies) version 21. Results: 142 questionnaires were distributed among people of children hospital and ICH Lahore. Most of the respondents were 25 to 35 years of age. Majority respondents show positive relationship towards work engagement and negative association with work alienation. Conclusion: The current study results showed that people of children hospital have good knowledge about the value of work engagement and work alienation in the criteria of work performance areas.
\end{abstract}

Key terms: work alienation, work engagement, work performance, health care worker.

DOI: $10.7176 / \mathrm{JHMN} / 80-06$

Publication date:September $30^{\text {th }} 2020$

\section{INTRODUCTION}

According the most recent studies a employee level of desertification and satisfaction at work place is psychological factor. In the sense some workers are feeling like pride in their working and some are behaving like alienate like having not concern about work responsibility.(Hakanen, Bakker et al. 2005) In the field of organizational working ares afters 2000 slingmen introduced the positive psychology about behaviors and its affects. . (Seligman 2000)

Work engagement has been presented in organization with different kind of perceptions such as job burnout, workaholism, organizational commitment organizational engagement, job satisfaction, job involvement, flow , and job performance .(Kadirioğlu, Kartal et al. 2018, Kartal 2018)

The word Alienation originate rom Latin pronoun 'alienate' and verb 'alienarer'. The meaning of this term mean leaving one's ownership to another and dissolving or separating between two things, respectively. 'Alienare' means the replace one to another.(Kartal 2018)

According to previous studies like Seeman (Seeman 1976), there are five sub-dimensions of alienation, as indicated in his work. These are powerlessness, meaninglessness, normlessness, isolation, and self- estrangement. The feeling of powerlessness, the expectations of the individual, and the possibilities that are thought to be realized are determined by others, and it is inevitable for the person to feel incapable of changing it. Seeman M. Alienation motifs in contemporary theorizing: the hidden continuity of the classic themes. (Seeman 1983)

The purpose of this research to examine the effect of work hostility and work engagement on structural health. The execution this project is piloted in area of nurses and physicians who are working in a public hospital and that data gathered from 142 people which is evaluated. The Participants that are health professionals working in children hospital and institute of child health Lahore.

This is a government hospital. Analysis of this research shows an expressive and positive relationship of the engagement of health professionals performance, and effects of work alienation as well. A regression analysis showed that the level of participants' for work engagement and work alienation had a significant direction on health care performance $(\mathrm{P}<0.00)$. The value of Cronbach,s alpha for work alienation, work engagement and perceived performance of healthcare professionals is greater than $0.839 \%$.thus results meet the standard requirement of reliability and this study variable are reliable.

In today's business world, increasing gratitude of obligation to exploit the possible organizational human resources, that is a great choice for detection of objectives to enhance efficiency and new aptitude, it has focused on usefulness in the managing are of the employees and also check the performance of them. In the area of working there is a huge negative relationship with work neglecting and positive with work devotion. Organizational success and failures have a close and significant relationship between them. Work performance has environment based working conditions and both have positive and negative impact on worker.

In today's business of world, increasing acknowledgment of requirement and pay attention of workers on their job demands is really needed, there are many factors for taking attention of subordinates like to meet high dreams and wish to introduce invention on this earth will be make nature of work very accurate. Also, the 
increasing worldwide phenomenon of employee alienation, a state where an employee faces separation from one's job (Kanungo 1982)

Work alcoholic and work isolated persons both are quite difficult in playing their role on job competition like race of promotions and demotions. This has made professionals realize, that preventing employee alienation and improving employee engagement are crucial in making the workforce to operate on highest possible level without sacrificing ethical boundaries.

Work commitment; is really satisfying and decent side of passion. It has a deep and related shadow in anyone behavior .that express deplane and uniformity in life. The think of an human being to divide his thinking to use power for good some big and daily task equally is justice with God given gift.

Effort and employee assignation are relevant measurement techniques for employees' mental health and therefore play a huge role in organizational behavior studies in general (Bakker, Schaufeli et al. 2008). Employee engagement's origins are linked to positive psychology theories and have been found to have substantial effect on the individual's psychological strength building(Maslach, Schaufeli et al. 2001) Positive psychology essentially stands for everything successful and well operating on human resource management level within an organization.

Work alienation The instant feeling in a person for not to do work even he is able to get it is very useless flash of brain. sometime ignorance about work is relaxation of stresses but if it is penetrate inside it will became a wound or like diseased case of body.

In the dimension of powerlessness weakening of employee quality and delay in work is releases that he is not able to judge the worth of work. A separation in a given tasks on working are reflect that he is a kind of people who is not given much values to his culture and norms as well.

Work engagement and work alienation were independent variables which was among the people of children hospital and ICH Lahore and work performance was dependent variable in the research study.

Work arrangement has a useful impetration to worker presentation in an organization and work alienation has a bad feeling as well. work meeting is motivated by using employee's hand, mind and heart dexterity with each other. Basically work alienation creates a trouble for organization that made it failure due to less interest in it like follow policy, give services and maintain quality of work that make the compromised performance of an individual in an organization.

It create a association in work hungers and work performance as like as destructive association in strength alienation on work performance.

1. The thought to have study in the health care organization areas for detecting a co- relation in work enthusiasm and in cut off jobs demands.

2. It has also to check connection in work devotion, disappointment by not full fill it anticipated goals and shadow on actions

This study provide an understanding there is more chances of increasing failure of any organization by work alienation that create a bad and low image on performance. Work rendezvous enhances effective work performance in an organization of workers .but how can we overcome these arising of work alienation between workers and increase work productivity.

\section{LITERATURE REVIEW:}

Working phase itself create a nice and healthy atmosphere in an organization and work alienation has a negative impact as well. It is motivated by means of employee's hand, mind and heart dexterity with each other. Basically work alienation creates a trouble for organization that made it failure due to less interest in it like follow policy, give services and maintain quality of work that make the compromised performance of an individual in an organization.

When healthcare professionals are working well in an organization then patient care not compromised and health ratio increased day by day.it give a great perception to operative hands how and which way that make easy for them. this is also inner satisfaction of a persons and take heart feeling which money he or she is received is really make his or himself happier either questioned mark in front of others and soul .

It has a clear vision there is a lot of open doors about a healthy relationship in organizational behavior by positive concern in job demands. it is seriously a pathetic and negatively affected on performance.(Rogers 1995) .

There is a vast requirement to enrich the rendezvous of worker about job due to decrease the resignation of employees and improve the performance.(Wright and Cropanzano 2000) (De Lange, Taris et al. 2003);(Griffith 2004) (Wall, Michie et al. 2004).

According to history a small educated research had conducted in the are of working. What is the meaning of work engagement? so , it has a good mean that is to lease a parson to do a job. When we opens our mind for such a uncanny thoughts, feelings, questioning and conventions and involving. That is fact people are mentally well involve and clear about that why we are engage them with work and what we expected from them .it is 
helpful to emerge the working criteria and level(Kahn 1990).

Jobs demands always put individuals with a lot of stressors like time management and hardworking .these stressors are get a positive output in performance of worker (Kahn 1990).

\section{METHODOLOGY:}

This education is conduct to Evaluating the authentic level of healthcare professionals in recital or feeling of rejection to do a task and also to do a assignment happen.

It is a quantitative co- relational research design. It will be following Physicians, Nurses, other health professionals. Administrative personnel working at the different area of hospitals.

My target population will be above given designation in hospitals. The participant will be belonging to the different hospital and different demographic background. The participant will be male and female. Data will be collected from participant through adapted questionnaire and participant through convenient method. The sample size for the study will be 142 which is calculated from the solvins method.

We informed participants that their given information will remain confidential and decided to distribute 142 questionnaire in children hospital physician and nurses according slovin,s .who agree to participated in this study .An adapted questionnaire was used to collect data by asking question .questions are set in four section one by asking demographical data like Age, gender, qualification ,experience and material status, second for work Engagement, third is work alienation and four on work performance .there will be given a free hand to complete it and return it.it used Likert scale .

Data collection plan is one of the main source to collect data . self administered questionnaire will be used to collected data from the participant there will be given a free hand to complete it and return it.it has willing to participant, those who understand English, Nurses and doctors of children hospital Lahore. It will be taken approximately $3-4$ months.

Consent will be informed to all before given them about related study questionnaire .they have right to fill and reject .it is up to them to wrote their demographic data or not. All information given by them will be keep confidential. The participant are fully acknowledge about criteria.

Sufficient literature and information regarding research will be given to all the participants after taking full consent with help of full consent by a standard consent from with questionnaire. Confidentiality would be considered an essential while taking to the participants.

Data analysis will be done SPSS version 20.statistical computer software for statistics exploration .that is a quantitative co-relational learning and all qualitative figures will be obtained through the SPSS software. The use of analysis aimed to work possession, dislikes and effectiveness in form of actions.

\section{DEMOGRAPHIC ANALYSIS:}

In given tables summarizes the characteristics of respondent $(n=142)$ on the basis of gender ( male and female ), Age ( 18-25 yrs., 25-35 yrs , 35-50 yrs , and above 35 yrs of age group ) Marital status ( Married and Signal ), Qualification ( Nursing diploma, Specialization, Post RN degree, and Others ) and Work experience ( less then 1 year, 1-5 years, 6-10 years and above 10 years). 
Demographic Characteristics of respondent

\begin{tabular}{|l|l|l|}
\hline & N & $\%$ \\
\hline & 142 & 100 \\
\hline Gender & & \\
\hline Male & 30 & 21.1 \\
\hline Female & 112 & 78.9 \\
\hline Age & & \\
\hline $18-25$ yrs. & 27 & 19.7 \\
\hline $25-35$ yrs. & 18 & 66.2 \\
\hline 35-50 yrs. & 18 & 12.7 \\
\hline Above 35 yrs. & 3 & 2.1 \\
\hline Marital status & & \\
\hline Married & 43 & 30.3 \\
\hline Single & 99 & 69.7 \\
\hline Qualification & & \\
\hline Nursing diploma & 86 & 60.6 \\
\hline Specialization & 30 & 21.1 \\
\hline Post RN degree & 23 & 16.2 \\
\hline Others & 3 & 2.1 \\
\hline Experience & & \\
\hline Less than yrs. & 35 & 24.6 \\
\hline 1-5 yrs. & 51 & 35.9 \\
\hline 6-10 yrs. & 36 & 25.4 \\
\hline Above 10 yrs. & 20 & 14.1 \\
\hline
\end{tabular}

RELIABILITY and VALIDITY ANALYSIS:

The value of cronbach,s alpha for work alienation, work engagement and perceived performance of healthcare professionals is greater than $0.70 \%$.thus results meet the standard requirement of reliability and this study variable are reliable.

Summary of Reliability analysis:

\begin{tabular}{|l|l|}
\hline Variables & Cronbach Alpha \\
\hline Reliability of work alienation & .812 \\
\hline Reliability of work engagement & .931 \\
\hline Reliability of work performance & .839 \\
\hline
\end{tabular}

\section{VALIDITY:}

In convergent of each variables was analyzed by preforming analysis. Factors analyzed was applied on all items. the instrument was consisting on two independent and one dependent variable . in result of validity test significance is .000 and the $\mathrm{df}$ is $210, \mathrm{KMO} .804$ of Work alienate professionals, and significance is .000, Df 153 , KMO .916 of that worker who are engaged their work and also significance result is .000, Df 45 and KMO is .847 of performance of worker. Assumption prove that KMO value is above then .50 Bartlett's test is $(p<0.05)$.the instrument of this study are valid.

\begin{tabular}{|c|c|c|c|c|}
\hline \multicolumn{2}{|c|}{ Correlation } & WA & WE & WP \\
\hline \multirow[t]{3}{*}{ WA } & Pearson correlation & 1 & $.700^{* *}$ & $.628^{* *}$ \\
\hline & Sig .( 2 tailed $)$ & & .000 & .000 \\
\hline & $\mathrm{N}$ & 142 & 142 & 142 \\
\hline \multirow[t]{3}{*}{$\mathrm{W}$} & Pearson correlation & $.700^{* *}$ & 1 & $.738^{* *}$ \\
\hline & Sig. (2-tailed) & .000 & & .000 \\
\hline & $\mathrm{N}$ & 142 & 142 & 142 \\
\hline \multirow[t]{3}{*}{ W } & Pearson correlation & $.628^{* *}$ & $.738^{* *}$ & 1 \\
\hline & Sig.(2 tailed) & .000 & .000 & \\
\hline & $\mathrm{N}$ & 142 & 142 & 142 \\
\hline
\end{tabular}

\section{Summary of KMO Bartletts,s test}

\section{CORRELATION}

The analysis of pearson correlation confirmed that there is exist significant positive relationship between the 
independent and dependent variables as value of WE is .700, WA 1 and WP .628 and P value is less than 0.05 .

\section{REGRESSION ANALYSIS:}

Regression analysis used to exposed and examine the related factors between variables . To examine and direct effect of work Alienation and work Engagement on the enactment of health care worker.

\section{COEFFICIENT}

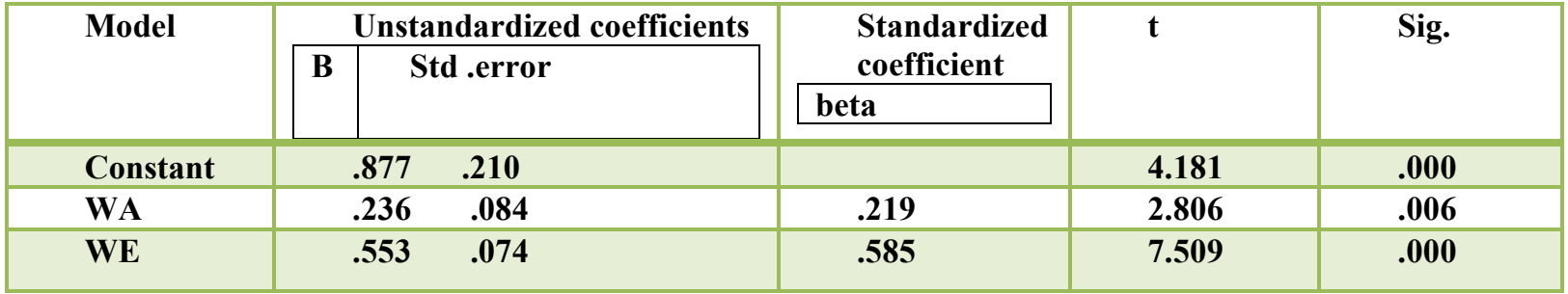

\section{a. Work Alienation}

b. Work Engagement

The table shows that independent variables like work alienation occur then .219 and if work engagement occur then .585 effects produced .

MODEL SUMMARY :

\begin{tabular}{|c|c|c|c|c|c|}
\hline Model & R & R square & $\begin{array}{c}\text { Adjusted R } \\
\text { square }\end{array}$ & $\begin{array}{c}\text { Std . Error } \\
\text { of the estimate }\end{array}$ & $\begin{array}{c}\text { Durbin- } \\
\text { watson }\end{array}$ \\
\hline 1 & $.754 a$ & .569 & .563 & .51577 & 1.778 \\
\hline
\end{tabular}

a. predictors. (constant), WE,WA

b. Dependent variable :WP

ANOVA

\begin{tabular}{|c|c|c|c|c|c|}
\hline Model & $\begin{array}{l}\text { Sum of } \\
\text { square }\end{array}$ & Df & $\begin{array}{l}\text { Mean } \\
\text { square } \\
\end{array}$ & $\mathbf{F}$ & Sig \\
\hline regression & 48.851 & 2 & 24.426 & 91.820 & $.000 \mathrm{~b}$ \\
\hline residual & 36.976 & 139 & .266 & & \\
\hline Total & 85.827 & 141 & & & \\
\hline
\end{tabular}

a. Dependent variables :WP

b. predictors(constant), WE,WA

The result in model summary shows that the current result that total .569 and table of ANOVA shows 91.820 exhibit the variation in the work performance of the healthcare professionals due to work Alienation and work engagement. ANOVA is significant $(p<0.266)$ that represents that the research model is fit / significant.

\section{DISCUSSION}

Sometimes thinking and living style of anyone amused us.it could be possible it get attention ally and unintentionally attraction level for audience. That place some temporary and permanent image's on others mind.it is a very important to know the duty of ours.in fact, if we realize the dutifulness purposes then we will make easy decision in work engagement, work alienation and impact as well on jobs performance. As a whole it is needed to assemble and recognized it to evaluate actually job description of a person, in health care this study is highly required to approach and full fill the facts and demands. Because when we dedicate our self then performance level get up grade remarks in the light of patient good response and by administration like appreciation form. If we neglect it demands then it create a ugly side in front of patient and administration .that is also very necessary to check and satisfied about incentive that are received by employees .they are dedicated then it create a positive relation otherwise in case of isolation not good for authority and employee.

\section{CONCLUSION}

The problem of ongoing time is we are every time in hurry .we just took a tiny second for conform about that thing is suitable for us and not? Same likely if any kind of work is touch to ours mind and soul then we do work madly and in other hand it is not make feel then we will alienate or isolate our self from it.however it is important .In working place many times it happen .workers waste their time on that task that is not necessary in their job .so, work did with ambitious feeling it could be possible level of performance get very large volume and work ignored or by mistake ignored then it enhance low impact in performance. 


\section{SUGESSIOTION AND RECOMIDATION}

We appreciate the dedication and hard work that all the members of our staff give the dedication and engagement of employees for work look like work holic that make them sick and made only for work. They do not have any other thought out of box in their head. They take work in their head and ignore their personal life., another hand of this if people are alienate them from their work then it has a negative impact on their performance like in hospital patients are suffered, both situation are discussed and measured in very deep detail in it ,but I would like to keep a little suggestion which is that the alienation of work has a low 1 evel as per work rendezvous has a positive impact. We keep a balance in both .if we are totally alienate or engage yourself from our work it has a negative and positive effect. But we need balance that maintain our skills and enhance our performance. We have a short time and limited questionnaire too that are not enough to collect proper data from hospital population .we should also take a note on it.

\section{Refrencess}

Bakker, A. B., et al. (2008). "Work engagement: An emerging concept in occupational health psychology." Work \& stress 22(3): 187-200.

De Lange, A. H., et al. (2003). "' The very best of the millennium": longitudinal research and the demandcontrol-(support) model." Journal of occupational health psychology 8(4): 282.

Griffith, J. (2004). "Relation of principal transformational leadership to school staff job satisfaction, staff turnover, and school performance." Journal of educational administration 42(3): 333-356.

Hakanen, J. J., et al. (2005). "How dentists cope with their job demands and stay engaged: The moderating role of job resources." European journal of oral sciences 113(6): 479-487.

Kadirioğlu, F. T., et al. (2018). "An improved earthquake catalogue ( $\mathrm{M} \geq 4.0)$ for Turkey and its near vicinity (1900-2012)." Bulletin of Earthquake Engineering 16(8): 3317-3338.

Kahn, W. A. (1990). "Psychological conditions of personal engagement and disengagement at work." Academy of management journal 33(4): 692-724.

Kanungo, R. N. (1982). "Measurement of job and work involvement." Journal of applied psychology 67(3): 341.

Kartal, N. (2018). "Evaluating the relationship between work engagement, work alienation and work performance of healthcare professionals." International Journal of Healthcare Management 11(3): 251-259.

Maslach, C., et al. (2001). "Job burnout." Annual review of psychology 52(1): 397-422.

Rogers, J. K. (1995). "Just a temp: Experience and structure of alienation in temporary clerical employment." Work and occupations 22(2): 137-166.

Seeman, M. (1976). Empirical alienation studies: An overview. Theories of alienation, Springer: 265-305.

Seeman, M. (1983). "Alienation motifs in contemporary theorizing: The hidden continuity of the classic themes." Social Psychology Quarterly.

Seligman, M. (2000). "Positive psychology, positive prevention, and positive therapy. Chapter prepared for CR Snyder \& S. Lopez." Handbook of positive psychology.

Wall, T. D., et al. (2004). "On the validity of subjective measures of company performance." Personnel psychology 57(1): 95-118.

Wright, T. A. and R. Cropanzano (2000). "Psychological well-being and job satisfaction as predictors of job performance." Journal of occupational health psychology 5(1): 84 . 